\title{
Current and evolving strategies in the management of severe mitral annular calcification
}

\author{
Kareem Bedeir, MD, MS, Tsuyoshi Kaneko, MD, and Sary Aranki, MD
}

\author{
From the Department of Cardiac Surgery, Brigham and Women's Hospital, Harvard Medical School, Boston, \\ Mass. \\ Received for publication Feb 21, 2018; revisions received May 15, 2018; accepted for publication May 28, 2018; \\ available ahead of print Oct 29, 2018. \\ Address for reprints: Sary Aranki, MD, Division of Cardiac Surgery, Brigham and Women's Hospital, 75 Francis \\ St, Boston, MA 02115 (E-mail: saranki@ partners.org). \\ J Thorac Cardiovasc Surg 2019;157:555-66 \\ $0022-5223 / \$ 36.00$ \\ Copyright (C) 2018 by The American Association for Thoracic Surgery \\ https://doi.org/10.1016/j.jtcvs.2018.05.099
}

Video clip is available online.

The oldest mitral valve (MV) examined and found to have mitral annular calcification (MAC) is that of an ancient Egyptian woman who lived almost 4000 years ago. ${ }^{1}$ Although this was reported in 2011, the earliest description of MAC in the literature was in 1908 by Bonninger and colleagues. ${ }^{2}$ Despite more than a century passing since then, MAC remains a daunting challenge that is neither fully understood nor is its management agreed upon. The objective of this article is to review the pathophysiology of MAC, the associated technical challenges, surgical techniques and outcomes, as well as future directions and potential solutions (Video 1).

\section{WHAT IS MAC}

MAC is a calcific degenerative process of the MV seen in almost $10 \%$ of the population, and in up to $40 \%$ in septuagenarians. $^{3-5}$ Calcification primarily affects the annulus, more commonly the posterior annulus, whereas the leaflets (especially anterior leaflet), commissures, and subvalvular apparatus are less commonly affected, distinguishing MAC from rheumatic mitral calcification.

Pathological and clinical descriptions have largely been understood through autopsy examinations by Roberts and colleagues $^{6-8}$ and MacVaugh and colleagues, ${ }^{9}$ as well as the clinical observations of Carpentier and colleagues. ${ }^{10}$ Calcium deposition in the atrioventricular (AV) fibro-fatty groove is typically included within a sheath, and can be removed en bloc if the correct plane is followed. On the annular plane, among MVs with MAC requiring mitral intervention, $<5 \%$ exhibit a complete circumferential calcium bar, whereas most bars are restricted to the posterior annulus (Figure 1, $A$ ). On the same plane, the circumflex coronary artery is in close proximity to the calcium bar,

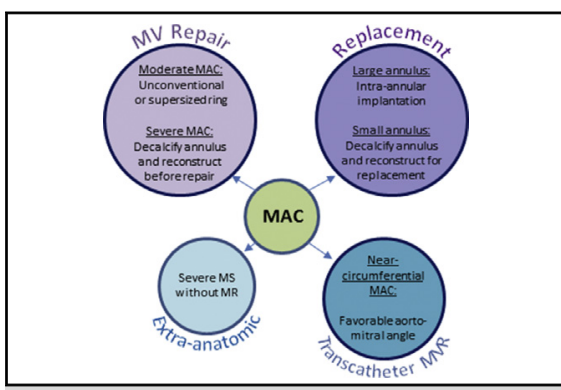

Proposed algorithm to address severe MAC during mitral valve surgery.

\section{Central Message}

Severe MAC is a complex problem that requires an armamentarium of tools. The cardiac surgeon of this era should be facile with multiple methods to manage patients with severe MAC.

\section{Perspective}

Severe MAC poses challenges that lack a consensus solution. We review the current and evolving strategies to address severe MAC during mitral valve surgery.

See Editorial Commentaries pages 567,568 , and 570 .

especially anterolaterally near the $\mathrm{P} 1$ area. The artery can be less than $1 \mathrm{~mm}$ away from the annulus especially with a large dominant circumflex vessel. On the vertical plane, the calcium bar is restricted to the annulus in almost $80 \%$ of cases (Figure 1, B). Extension into the base of the posterior leaflet or subvalvular apparatus is seen in almost $5 \%$ of cases. In almost $10 \%$, the calcium bar extends into the ventricular myocardium, and importantly loses encapsulation making enucleation challenging.

Several grading classifications have been proposed, on the basis of circumferential extension, vertical extension, or bar density. ${ }^{11-13}$ So far, none of these classifications is universally adopted.

\section{ETIOLOGY AND ASSOCIATIONS}

The etiology of MAC is not entirely understood and is likely multifactorial. Some factors that play a role in the pathogenesis of MAC as well as common associations are known. Being a degenerative process, increased age is an independent predictor of MAC in all ethnicities. ${ }^{14,15}$ 


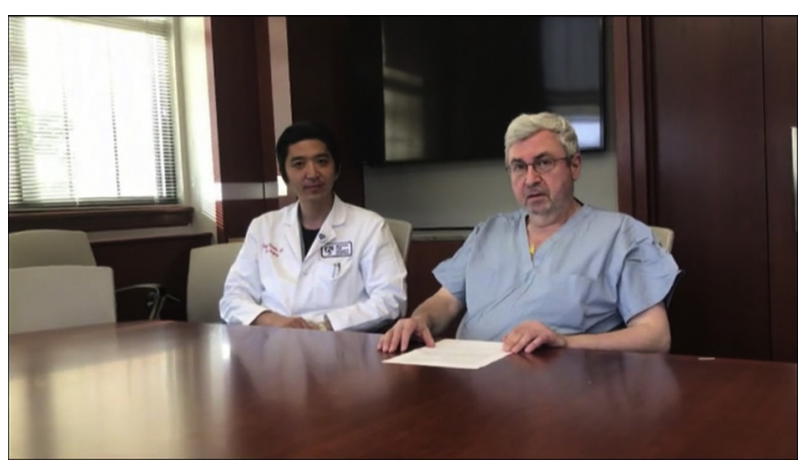

VIDEO 1. Authors summarizing the key points of this review addressing mitral interventions with severe mitral annular calcification. Video available at: https://www.jtcvs.org/article/S0022-5223(18)31545-9/fulltext.

There is ample evidence to support the theory that MAC and atherosclerosis are parts of the same disease process, because of their association with each other, similar associations to other conditions, similar risk factors, and similar effect on cardiovascular risks in terms of aortic, carotid, coronary, and peripheral arterial diseases. ${ }^{15-18}$ Also being degenerative, there is evidence to support that increased stress on the MV annulus increases the prevalence, progression, and severity of MAC, leading to an observed association between MAC and systemic hypertension, aortic stenosis, left ventricular (LV) hypertrophy, and mitral regurgitation. ${ }^{19-23}$ In addition, MAC is associated with atrial fibrillation and conduction abnormalities. ${ }^{24-26}$ The common association of MAC with these morbidities makes MAC itself a marker of a poor cardiovascular status and reserve. In the Framingham Heart study 16-year follow-up it was reported that for every $1 \mathrm{~mm}$ increase in MAC, there is a $10 \%$ increased risk for cardiovascular disease (hypertension, coronary artery disease, and peripheral arterial disease), cardiovascular mortality, and all-cause mortality. ${ }^{5}$

Chronic kidney disease is another important contributing and associating factor. The increased calcium phosphorus product in renal disease is thought to enhance calcium deposition at areas of stress, with a linear relationship between MAC and creatinine clearance, which independently predicts poor outcomes. ${ }^{27-31}$ Radiation, especially mediastinal radiotherapy for cancer has also been associated with MAC, which is predominant in the anterior annulus and in the intervalvular fibrosa. ${ }^{32,33}$ This was shown to be an independent predictor of cardiovascular mortality in patients who had received radiation and were to undergo cardiac surgery. ${ }^{34}$ Other congenital syndromes like Marfan and Hurler syndrome are also independently associated with MAC. ${ }^{35-37}$

MAC is not the primary pathology responsible for MV disease in most cases. When MAC is associated with a mitral hemodynamic abnormality, it is commonly associated with mixed regurgitation and stenosis, followed by

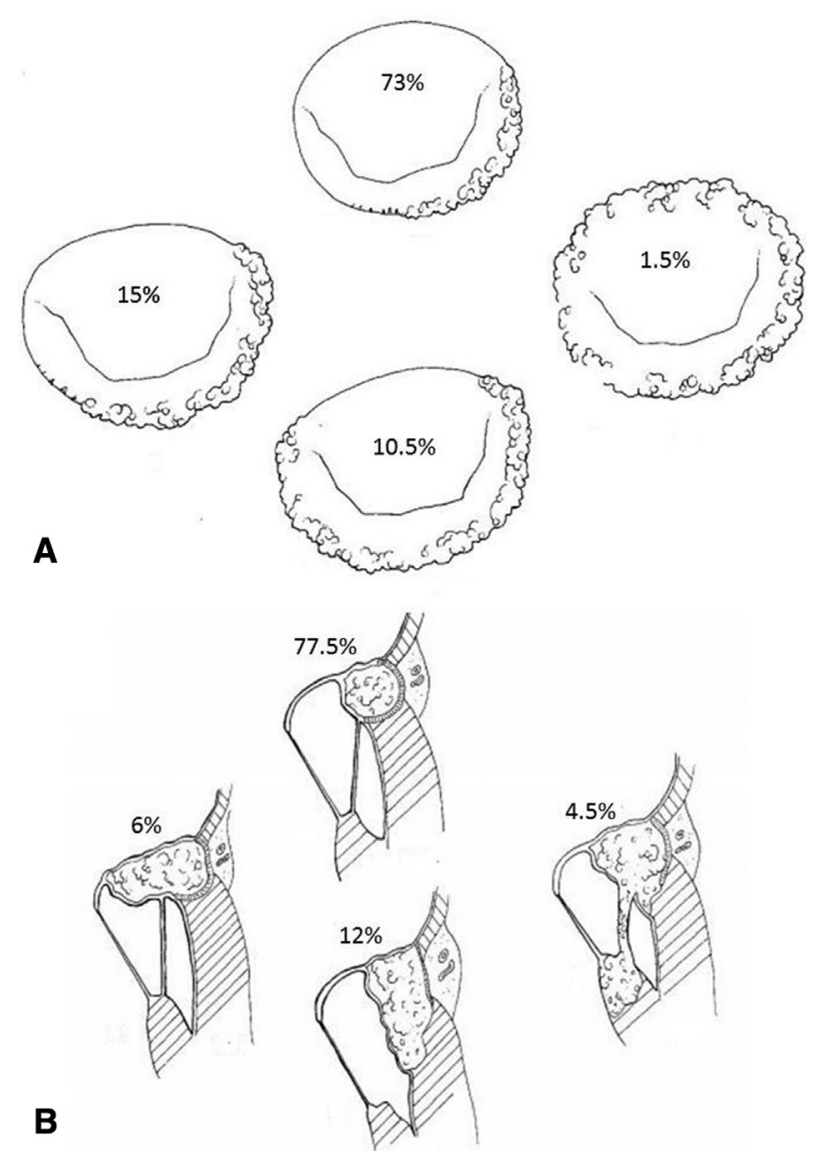

FIGURE 1. Distribution prevalence of mitral annular calcification in the annular (A) and the vertical (B) planes. Adapted with permission from Carpentier et al. ${ }^{10}$

purely regurgitant lesions and less commonly purely stenotic lesions. ${ }^{6,10,17}$ Because MAC itself is typically not the cause of the hemodynamic abnormality, characteristics of these abnormalities, like in non-MAC patients, depends on the etiology of the lesion. In the series by Carpentier and colleagues, ${ }^{10} 93 \%$ of the MVs had other pathologies that lead to valve dysfunction, with MAC representing a bystander that complicated surgery. In the less common patients without another identified etiology for valve dysfunction, MAC itself can cause stenosis, regurgitation, or more commonly a combination of both. Proposed mechanisms include failure of annular systolic contraction (regurgitation) or diastolic relaxation (stenosis), leaflet basal involvement leading to restriction of mobility, as well as annular geometrical distortion. Fortunately, most patients with MAC do not require mitral intervention. In the small percentage of patients who do require intervention, significant challenges are encountered. Regardless of whether these morbidities are causal or associates, a patient with MAC is likely at an increased risk of morbidity and mortality because of multiple systemic factors and local mechanical factors. 


\section{MANAGEMENT WITH MAC Technical Challenges}

Almost $20 \%$ of patients who undergo MV surgery have some degree of MAC. ${ }^{23,38}$ Those with severe MAC are especially challenging, and even in the hands of the most experienced surgeons, the poor baseline health status and the surgical complexity are reflected in longer bypass times and higher mortality rates. ${ }^{7,39}$ The mortality rate for isolated MV surgery in the Toronto experience was $9 \%$ in patients with MAC as opposed to $1.5 \%$ in patients without MAC in the same center over the same period. ${ }^{39}$

Challenges with MAC start before surgery. Echocardiography, the gold standard for diagnosis, is complicated by acoustic shadowing, which makes measurements difficult or erroneous, necessitating multiple approaches, including transesophageal echocardiography. Because of the prevalence of concomitant porcelain aorta, carotid disease, and coronary artery disease, preoperative computed tomography (CT) angiography as well as coronary catheterization are often routinely done for any patient with MAC. Preoperative CT angiography (and perhaps 3-D printing) will likely be more standardized with the advent of transcatheter valves into the set of potential therapeutic options (Figure 2). ${ }^{11}$

In the operating room, challenges are encountered before direct examination of the MV. The surgical strategy should be carefully planned especially with concomitant procedures (coronary, valvular, aortic, or septal). Epiaortic ultrasound helps to avoid calcified areas of the aorta, and with extensive calcification, alternative cannulation strategies might be needed. During bypass, higher perfusion pressures might be required because of systemic atherosclerosis.

The MAC itself presents tremendous technical challenges. Implanting a valve on top of the calcium bar would lead to significant paravalvular leak (PVL) that is less likely to heal. Perhaps because of higher interchamber pressure gradient, PVL in the mitral position is significantly more ominous than that in the aortic position, and requires a more aggressive reintervention strategy. ${ }^{40}$ In addition, stitches around the calcium bar risk injuring the coronary sinus or conduction system posteromedially, and the circumflex artery anterolaterally. Preoperative coronary angiogram and intraoperative transesophageal echocardiography can help identify a large dominant circumflex artery in relation to the MAC. In such cases, lifting the heart with a valve or ring in place to bypass a circumflex injury is extremely high risk for $\mathrm{AV}$ groove disruption, especially if the MAC is debrided. Some surgeons partially ameliorate this risk by prophylactically bypassing the circumflex artery before addressing the MV, although it adds to the procedural complexity, bypass time, and morbidity. ${ }^{41}$

Annular decalcification allows for better valve seating and potentially better healing and less PVL. This, however, comes with the risk of weakening the annulus, thus increasing the risk for catastrophic AV groove disruption. With extensive decalcification, several methods for annular reconstruction are proposed to avoid this complication, but these come with various technical complexity requiring longer bypass times and technical expertise. ${ }^{10,11,42}$ Details of the technique are described in the next section.

Last, with the advent of transcatheter MV (TMV) interventions for a near-complete MAC ring, issues related to LV outflow tract (LVOT) obstruction (LVOTO) are lifethreatening. ${ }^{43,44}$ Septal hypertrophy, which is a problem commonly associated with MAC creates additional risk of LVOTO. $^{22}$ Obtaining CT angiogram with $3-\mathrm{D}$ printing is a very promising tool in estimating the neo-LVOT and predicting this problem.

\section{Techniques}

With minimal focal MAC, focal decalcification and direct closure with or without annular plication is a commonly described technique. ${ }^{45}$ Also, a decalcify-asneeded approach is sometimes adopted with focal decalcification just enough to allow needle passage. This, however, is suboptimal because of problems related to PVLs that are unlikely to regress as described earlier. For severe MAC, several techniques have been proposed to overcome these challenges. There are 2 main decisions that should be made: (1) whether to repair or replace the valve, and (2) how to address the heavily calcified annulus.

Repair or replacement. The presence of MAC should not lead to replacement of a repairable valve, regardless of the strategy chosen toward the annulus. In their report of 68 patients with severe MAC, Carpentier and colleagues repaired 67 valves and replaced $1 .^{10}$ In most instances, MAC does not significantly distort the leaflets and usually spares the commissures. Repair has been shown to provide superior outcomes over replacement in terms of survival, LV function, and prosthetic valve-related complications, and these should hold true in the presence of MAC. ${ }^{46-49}$ Feasibility of repair with similar excellent outcomes in patients with MAC has been shown in several series. ${ }^{10,45,50,51}$

Leaflet repair techniques are similar to those used for any $\mathrm{MV}$, including leaflet augmentation as described by Carpentier's group for rheumatic leaflet shortening. ${ }^{52}$ The main challenge with MAC, however, lies in mounting the annuloplasty ring. Leaflet-based repairs without a ring are simple, but have been shown to yield suboptimal outcomes especially with MAC in terms of durability and need for reintervention. ${ }^{53}$ Although challenging, every effort should be made to mount an annuloplasty ring if repair is to be done.

If decalcification is not done, especially with less than severe calcifications, an unconventional orientation of the annuloplasty ring has been described where the opening of a C-shaped ring is directed toward the P1 and anterior 

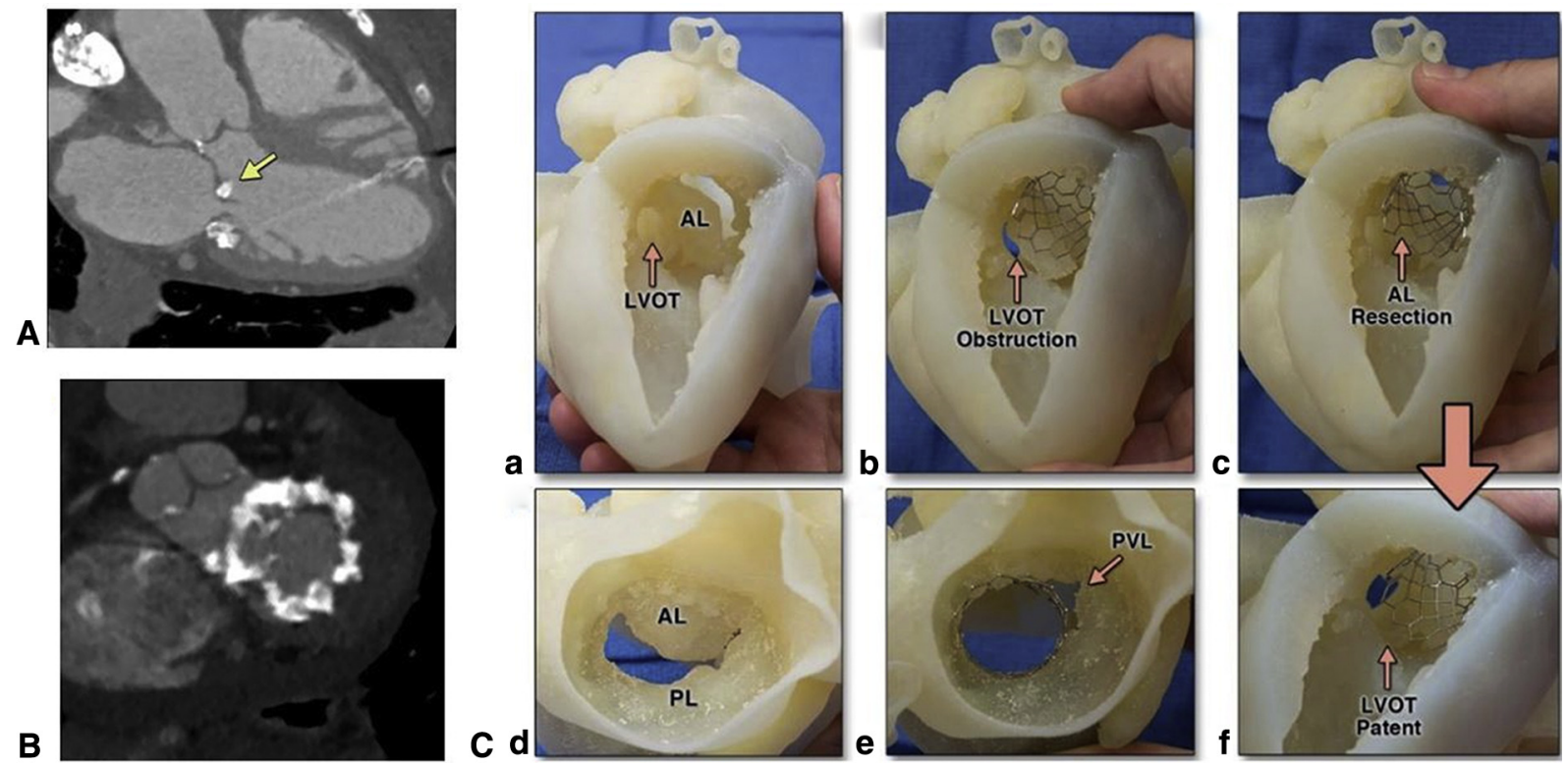

B
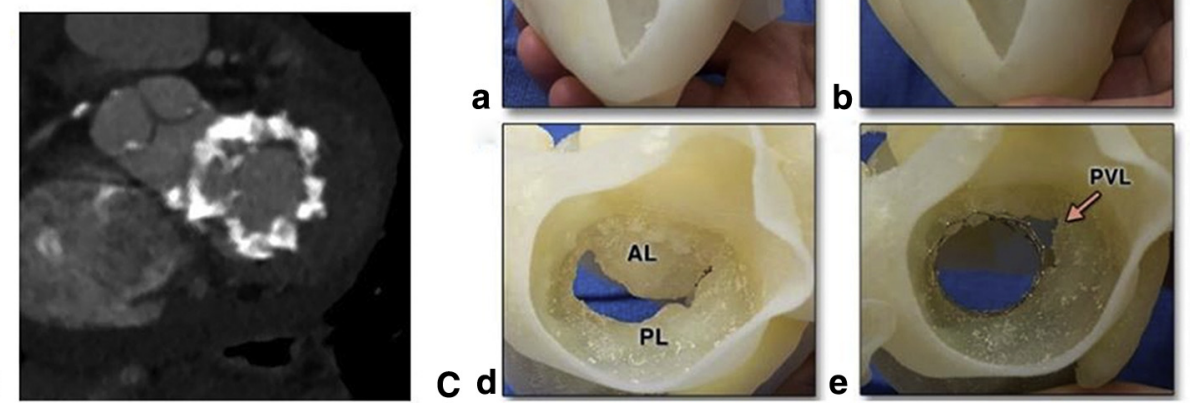

FIGURE 2. Cardiac computed tomography imaging and 3-D printing in mitral annular calcification (A and B): computed tomography imaging showing mitral annular calcium burden, distribution, and dimensions; (C) 3-D printing for surgical planning and management of various aortomitral angles, in anticipation of left ventricular outflow tract $(L V O T)$ obstruction. $A L$, Anterior leaflet; $P L$, posterior leaflet; $P V L$, paravalvular leakage. Adapted with permission from Eleid et al. ${ }^{11}$

commissural area thus minimizing the risk of circumflex injury (Figure $3, A) .{ }^{55}$ In addition, a super-sized ring-annuloplasty can be done, where a ring larger than the annular size is mounted outside of the calcium, with an accepted small but real risk of injury to periannular structures. ${ }^{55}$ Mounting stitches can be placed from the atrial side or be placed ventriculo-atrial with pledgets. With the latter, care should be taken not to disrupt the subvalvular apparatus with the suture or the pledget (see the video on unconventional and super-sized annuloplasty at: https://aats.blob. core.windows.net/media/17MC/2-1400-1410-eleshmawiq\&a-v1.mp4). If annular decalcification is undertaken, the posterior leaflet is detached from the annulus, and then the leaflet and the ring are reattached to the annulus after reconstruction. ${ }^{10,13}$

Addressing the annulus: "resect" or "respect." The plan toward the mitral annulus is the main dilemma with MAC. This is broadly categorized into 2 strategies: (1) decalcification with annular reconstruction- "resect strategy," and (2) avoiding annular decalcification- "respect strategy." The latter technique mitigates the potential for a catastrophic AV groove disruption, however has its own set of challenges and limitations.

Complete annular decalcification with annular reconstruction allows for better seating of the valve and less PVL, but is technically challenging, weakens the annulus, and predisposes to AV groove disruption. This will also shorten the distance to the circumflex artery, which increases its risk of injury. Decalcification is done using sharp dissection, and if in the correct plane, the bar can usually be removed en bloc, except when invading the ventricular myocardium. Decalcification has also been reportedly effective using ultrasonic pulverization using the Cavitron Ultrasonic Surgical Aspirator (CUSA; Cooper, Stamford, Conn; see the video on placement after sharp and CUSA decalcification, followed by Carpentier's figure-of- 8 annular closure at: https://www.youtube.com/watch? $\mathrm{v}=$ LoE21CfTX-g\&t=2079s). ${ }^{56-58}$

Whether repairing or replacing, preserving the posterior leaflet should be attempted and 2 incisions made, 1 to separate the annulus from the atrium and another to separate the annulus from the posterior leaflet. Depending on the depth of annular deconstruction, one can primarily close the decalcified annular defect using either a continuous suture, or preferably using the everting figure-of- 8 sutures described by Carpentier (Figure 3, A; see the video on placement after sharp and CUSA decalcification, followed by Carpentier's figure-of- 8 annular closure at: https://www. youtube.com/watch? $\mathrm{v}=$ LoE21CfTX-g\&t=2079s), or decide to reconstruct the annulus. Three techniques for annular reconstruction have been developed. The Carpentier method involves dissecting an atrial muscle flap, then using this flap to cover the deconstructed annulus (Figure 3, B). ${ }^{10}$ They reported excellent results in their report of 68 patients (67 repairs and 1 replacement). Mean cross-clap time was $78 \pm 37$ minutes. In-hospital mortality was $3 \%$ but no AV groove disruptions were encountered. At 7 years, survival was $93 \%$ and freedom from reoperation was $87 \%$. 


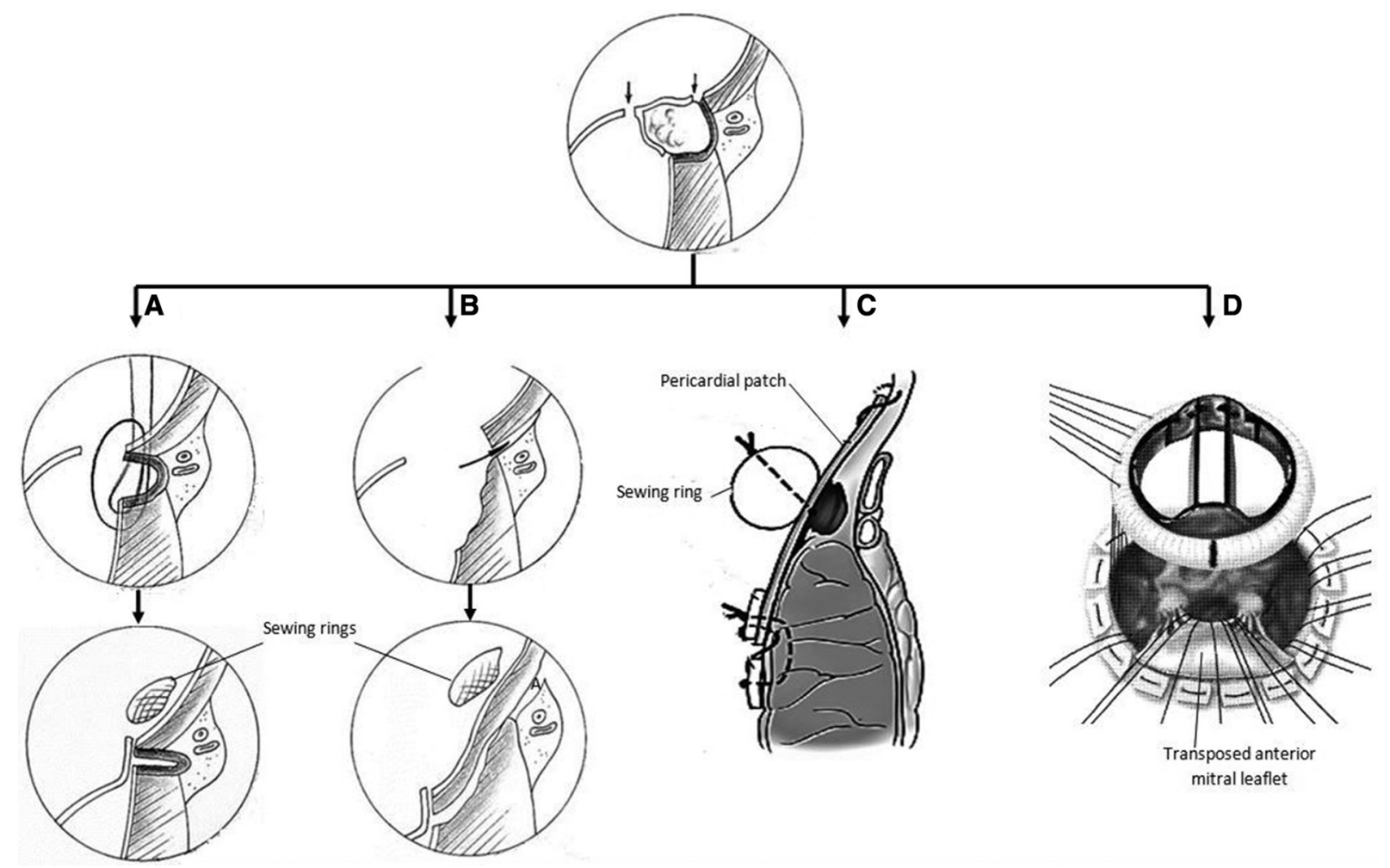

FIGURE 3. Reconstruction after significant posterior annular decalcification. A, Direct closure with figure-of-8 sutures (with less radical decalcification), (B) Carpentier's left atrial release technique, (C) David's pericardial patch technique, (D) Casselman's anterior mitral leaflet transposition. A and B, Adapted with permission from Carpentier et $\mathrm{al}^{10}$; (C) adapted with permission from Mihaljevic et $\mathrm{al}^{54}$; and (D) adapted with permission from Casselman et al. ${ }^{42}$

The second technique reported by Tirone David and colleagues involves reconstructing the posterior annulus trigone-to-trigone using a strip of bovine pericardium (Figure $3, C$ ) (see the video on valve repair after decalcification and posterior annular patch repair [David's method] at: https://www.youtube.com/watch? $\mathrm{v}=$ sbc0efxNW7w). ${ }^{39}$ Their report includes more advanced calcification requiring more complex repair, and this is reflected in worse outcomes. Of their 54 patients, only 12 underwent mitral repair, with the remaining underwent replacement. Thirtyone patients underwent posterior annular decalcification and reconstruction from trigone-to-trigone. The calcium extended circumferentially in 23 patients with variable extension into the intervalvular fibrosa requiring an additional patch to reconstruct the anterior annulus and the aortomitral curtain. Nineteen patients required a concomitant aortic valve repair or replacement. Mean cross-clamp time was $122 \pm 49$ minutes. In-hospital mortality was $9 \%$ (as opposed to $1.5 \%$ mortality reported by the same group in non-MAC mitral surgery). There were no reported AV groove disruptions with this technique. At 8 years, survival was $65 \%$, freedom from reoperation was $91 \%$, and freedom from valve-related morbidity or mortality was $74 \%$.
$\mathrm{Ng}$ and colleagues ${ }^{50}$ published excellent results in their report of 37 patients with MAC using a combination of the 2 techniques. Twenty-one patients required significant decalcification and reconstruction. Carpentier's method was used in 8 patients and David's in 13 patients. They reported no in-hospital mortalities. At 5 years, survival was $100 \%$ and freedom from reoperation was $95 \%$. Uchimuro and colleagues ${ }^{59}$ reported their results of 61 patients with severe MAC who underwent complete annular debridement using CUSA, with reconstruction of the posterior annulus using a pericardial patch. Near half of the patients underwent concomitant aortic valve replacement (AVR), and nearly a third underwent concomitant coronary bypass. They reported $7 \%$ in-hospital deaths after 30 days, 1 patient with $\mathrm{LV}$ rupture, $4 \%$ stroke rate, $5 \%$ renal failure requiring dialysis, and $8 \%$ heart block requiring permanent pacemaker.

The third technique reported from the Cleveland Clinic by Casselman and colleagues ${ }^{42}$ involves patching the deconstructed posterior annulus using the anterior mitral leaflet (Figure 3,D). They reported success of this technique in 20 patients with no $\mathrm{AV}$ groove disruptions. It is of note, however, that this technique requires a pliable anterior leaflet, and importantly commits to a valve replacement 
as opposed to a potentially possible repair. Overall safety and performance of this technique is also not adequately reported.

A relatively recent experience has been retrospectively reviewed and reported from the University of Pennsylvania group. ${ }^{60}$ In their presentation, they compared 130 patients with moderate or severe MAC with 1076 patients without MAC, all who underwent isolated MV surgery. They reported extensive decalcification using the CUSA device followed by large annular suture bites, without annular reconstruction. In their report, there was no significant difference in in-hospital outcomes between patients with MAC and those without except length of stay and time to extubation. There was no mention, however, of the rates of $\mathrm{AV}$ groove disruption, circumflex artery compromise, postoperative PVLs, and/or permanent pacemaker implantations.

The alternative approach toward the annulus is to avoid decalcification altogether to avoid catastrophic AV groove disruption as well as the significant technical complexity and morbidity associated with annular reconstruction. Unfortunately, the options for valve repair within the "respect strategy" are limited because of problematic mounting of the annuloplasty ring, although unconventional or supersized annuloplasties can be done as described earlier (Figure 4, A). Several techniques of valve replacement have been described while avoiding annular decalcification, unfortunately neither of which is optimal but are important options to have in difficult intraoperative situations. Drilling a 1-mm suture path into the calcium bar using a surgical driller and buttressed with a Teflon strip has been described in 3 patients. ${ }^{65}$ Intra-atrial implantation of the valve with sewing directly into the atrial wall has been described. ${ }^{66,67}$ Nataf and colleagues ${ }^{67}$ reported this technique in 21 patients. This resulted in a mortality due to atrial wall tear and intractable hemorrhage secondary to subjection to ventricular pressure. Also, almost $20 \%$ of the patients required early reoperation because of significant PVL, and thus, this technique is not recommended. Intra-annular insertion is another option attempted but significantly downsizes the valve and usually results in significant PVLs. Attempts to decrease PVL with intra-annular implantation led to several techniques being described. Coselli and Crawford ${ }^{61}$ reported success in 1 patient with securing the posterior aspect of the sewing ring to a folded posterior leaflet (Figure 4, B). A combination of intra-atrial and supraannular implantations has been reported to avoid the disadvantages of both. Di Stefano and colleagues ${ }^{62}$ sutured the posterior sewing ring of the valve to the folded posterior leaflet and the folded atrial wall and reported a good result in 1 patient with no PVL (Figure 4, C). Another strategy described to alleviate PVLs with intra-annular implantation is collar reinforcement, where the valve is sewn to the leaflet, and then a circumferential or posterior collar attached to the sewing ring is sewn to the supra-annular atrial wall, thus forming double-layer isolation between ventricular and atrial pressures (Figure 4, D) ${ }^{63,68}$ Hussain and colleagues ${ }^{68}$ reported their outcomes with posterior collar reinforcement in 20 patients. More than half of the patients underwent concomitant aortic valve, aortic root, or coronary interventions. There was no PVL using this technique. There was 1 in-hospital mortality, and after 5 years, actuarial survival was $50 \%$. Although both combinations of intra-atrial/intra-annular implantations did successfully minimize PVL, they lead to significant downsizing of the valve, which makes them only viable options with a large mitral annulus.

A last resort with severely hostile MAC that is predominantly stenotic with minimal regurgitation is to bypass the valve. This was initially described by Wright and colleagues, ${ }^{69}$ bypassing the left atrium from the right side to the LV apex using a graft with a valve equidistant from both cavities (Figure 5, A). This approach was modified by Said and Schaff ${ }^{70}$ using a terminally valved conduit and proximally connecting it to the left atrial appendage (Figure 5, B). The valve sutured flush to the ventricular cavity is thought to ameliorate some of the valve and LV geometry related problems thought to occur with the earlier technique (see the video on extra-anatomical bypass: https://aats.blob.core.windows.net/media/17MC/2-ghall-1515schaff-q\&a.mp4). Both techniques cannot be used with more than mild mitral regurgitation, and even if situations permit, these extra-anatomical bypasses are the least physiologic and should not be the standard go-to approaches.

In our experience, we have used a variety of the previously described techniques. We have not used the CUSA because we had disappointing results with calcific aortic stenosis. Another technique we never used is the extraanatomic valve-graft conduit from the left atrial appendage to the apex of the left ventricle in patients with severe MAC, severe mitral stenosis, and no regurgitation. Obviously, this technique requires utmost dexterity in graft length measurement to avoid catastrophic kinking of the graft upon closure of the sternum. We wonder if a similar last resort procedure can be performed in the presence of mitral regurgitation after obliterating the valve orifice.

TMVs. When replacement is necessary, transcatheter valves have recently become the most viable option in the "respect strategy." Despite the vast differences between aortic and MV respective anatomy and physiology that make mitral interventions more complex, initial reports of transcatheter techniques have shown promising results via percutaneous or open transatrial approaches (see the video on transatrial implantation of a Sapien transcatheter aortic valve in the mitral position https://www.youtube. $\mathrm{com} /$ watch?time_continue $=206 \& \mathrm{v}=$ If-k1LdrUjo). ${ }^{43,44,71-73}$ Multiple transcatheter valves specifically designed for the mitral position are currently under clinical investigation. However, most of these mitral-specific valve designs have 


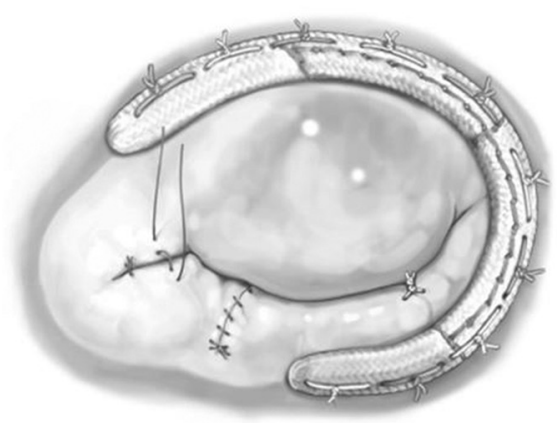

A
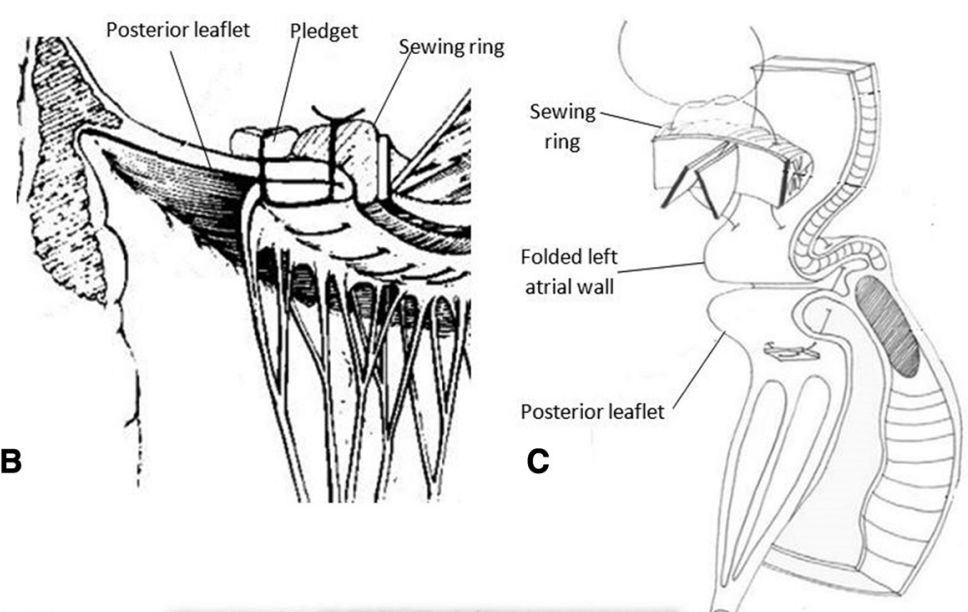
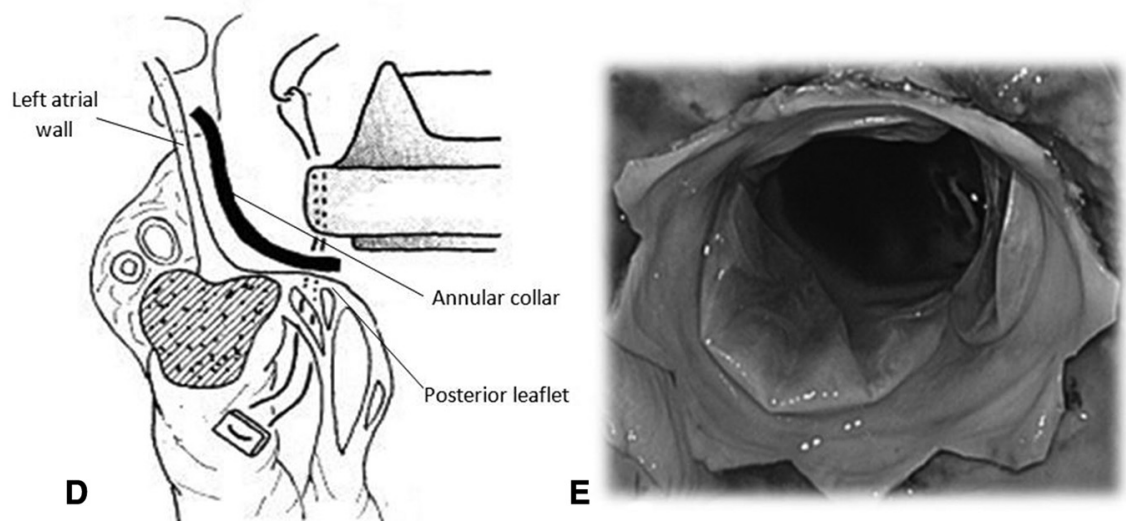

FIGURE 4. "Respect" strategies with avoiding decalcification. A, Unconventional annuloplasty to avoid posterior annular sutures near the P1 and anterolateral commissure. B, Intra-annular implantation; plicating the posterior mitral leaflet. C, Combined intra and supra-annular implantation, with posterior leaflet and left atrial wall plication. D, Intra-annular implantation; valve prosthesis with supra-annular collar to compensate for paravalvular leakage. E, Intra-annular implantation; balloon-expandable sutureless melody valve under direct vision (view from the left atrium). A, Adapted with permission from Carpentier et al. ${ }^{55} \mathrm{~B}$, Adapted with permission from Coselli et al. ${ }^{61} \mathrm{C}$, Adapted with permission from Di Stefano et al. ${ }^{62} \mathrm{D}$, Adapted with permission from Okita et al. ${ }^{63}$ E, Adapted with permission from El-Eshmawi et al. ${ }^{64}$

excluded severe MAC patients in their early feasibility studies. Valves used in the largest reports available included the balloon-expandable Sapien valves (Sapien, Sapien XT, and Sapien 3; Edwards Lifesciences, Irvine, Calif), which is an aortic valve in the mitral position, in more than $90 \%$ of the patients, as well as other valves including the Melody valve (Medtronic, Minneapolis, Minn), the Lotus valve (Boston Scientific, Natick, Mass), the Direct Flow valve (Direct Flow Medical, Santa Rosa, Calif), and the Inovare valve (Braile Biomedica, São Paulo, Brazil). ${ }^{43,44}$

The only available large data reported in severe MAC is in a multicenter retrospective study of 64 patients who underwent TMV implantation. ${ }^{43,44}$ In this registry, only the patients who were deemed not eligible for MV surgery were included. Their mean Society of Thoracic Surgeons score was $14.4 \pm 9.5 \%$. Access was transapical in $44 \%$, trans-septal in $41 \%$, and transatrial in $15 \%$. Although technical success was achieved in $72 \%$ of the patients, significant adverse outcomes were encountered. Thirty percent of the patients died within 30 days. Serious procedural complications were encountered including LVOTO $(9 \%$, in which 5 of 6 patients died), LV perforation (3\%; in which 2 of 3 patients died), and valve embolization ( $6 \%$; in which 3 of 4 patients died). Six percent of the cohort was converted to open mitral surgery. Nineteen percent of the patients had AVR done concomitantly ( $8 \%$ had surgical AVR, all having TMV via a transatrial approach, and $11 \%$ had transcatheter AVR, all having TMV via a transapical approach).

A few important lessons are learned from this registry. First, despite the skepticism, transcatheter aortic valves can be deployed in the mitral annulus despite its noncircular configuration. Although there was no clear inclusion parameter in this registry as to how much MAC is needed, the general practice was with near-circumferential involvement. A striking outcome in this registry is the complete absence of more than mild PVL, despite the valves used not being designed for the mitral position. When PVLs do occur, careful overexpansion of the valve with the balloon can also resolve small leaks. With larger leaks, the Amplatz device (St Jude Medical, St Paul, Minn) implantation, whether percutaneously or under direct vision, has been reported to yield acceptable outcomes with surgical valves and has been 


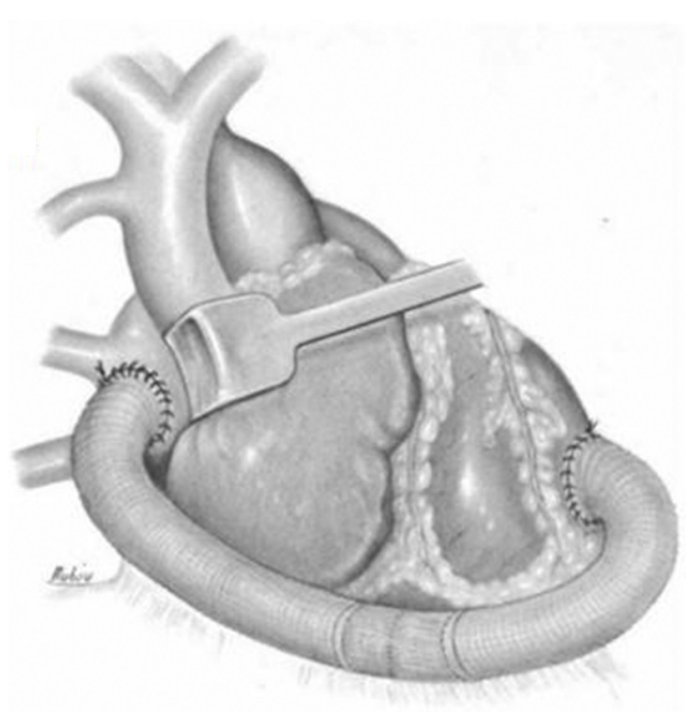

A

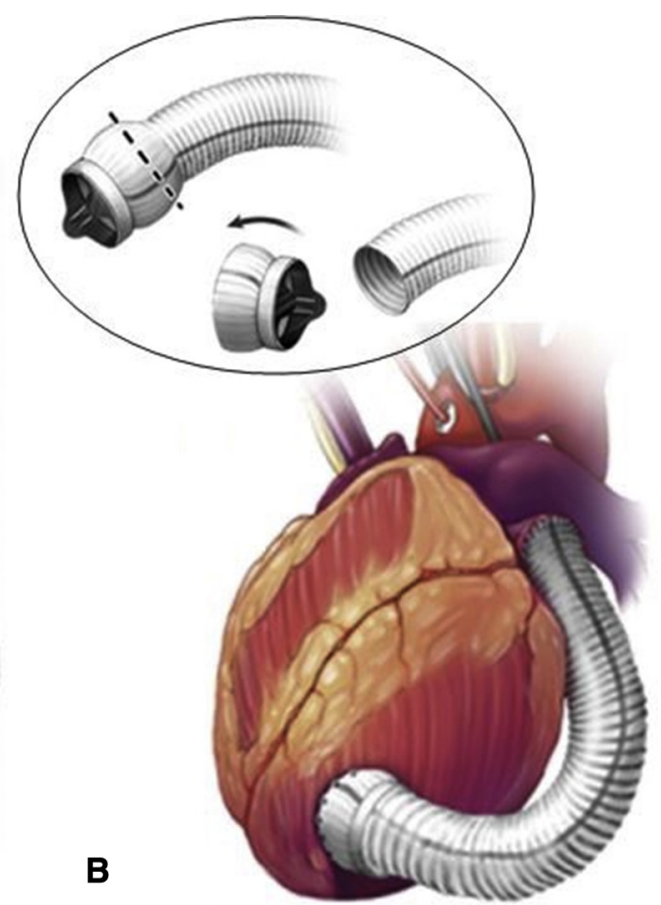

FIGURE 5. Extra-anatomical techniques for addressing mitral stenosis associated with extensive mitral annular calcification. A, Left atrial dome to left ventricular apex using a midvalved conduit. B, Left atrial appendage to left ventricular apex with a terminally-valved conduit. A, Adapted with permission from Wright et al. ${ }^{69} \mathrm{~B}$, Adapted with permission from Said et al. ${ }^{70}$

recently used with transcatheter mitral valve replacement (TMVR) as well. ${ }^{74,75}$ Although the transatrial approach in this registry seemed to have a highest success and lowest mortality, the sample size was too small to make this conclusion. Although this registry has almost the same amount of patients as the surgical series by Carpentier and colleagues, ${ }^{10}$ these 64 patients are from 32 centers with a mean of 2 patients per center. This would suggest that with increasing experience, the risk profile of TMV in MAC patients can be substantially improved.

Another lesson learned is the utmost importance of preoperative imaging to plan TMV implantation. Six patients of the 62 patients included in the registry had postimplantation LVOTO, of whom 5 died. This highlights the utmost importance of preoperative anticipation and prophylactic measures taken to prevent LVOTO. Cardiac CT should be considered routine, and predictors of LVOTO should be investigated (aorto-mitral angle, septal hypertrophy, anterior mitral leaflet, and others). Three-dimensional printing can add accuracy to predictors of LVOTO that might be difficult using echocardiography alone. ${ }^{11}$ With anticipated LVOTO, planning for preoperative septal ablation or intraoperative septal myectomy, the latter during transatrial implantation, can prevent or resolve LVOTO. Resection of the anterior mitral leaflet during the transatrial approach was also reported, which ameliorated LVOT narrowing, however, it resulted in higher than anticipated rates of significant PVLs. ${ }^{71}$ Another approach described to address an elongated anterior mitral leaflet in the setting of a potentially narrowed neo-LVOT is the intentional Laceration of the Anterior Mitral leaflet to prevent left ventricular Outflow tract Obstruction (LAMPOON). Babaliaros and colleagues ${ }^{76}$ reported the successful use of the LAMPOON to lacerate the anterior mitral leaflet along the center line from base to tip of the A2 scallop, using an electrified guide wire before transseptal TMVR in 5 patients with predicted prohibitive risk for LVOTO. In cases that are high risk for LVOTO and are neither appropriate for a transatrial approach nor a preoperative LAMPOON, surgical mitral valve replacement should be considered. In the unfortunate case in which LVOTO does occur after TMVR, septal alcohol ablation can be attempted in the stable patient. This might alleviate the gradient and avoid surgical correction. Double aortic and MV ballooning might temporarily relieve the gradient but with expected recoil. ${ }^{77}$ Surgical correction is unfortunately required for patients with post-TMVR LVOTO who are not eligible or in whom septal alcohol ablation has failed. We however emphasize that emergent surgery in these high-risk patients does not lead to optimal outcomes. This again highlights the utmost importance of careful preoperative assessment.

It is almost certain that with time the role of transcatheter techniques will expand to suit more patients and become 


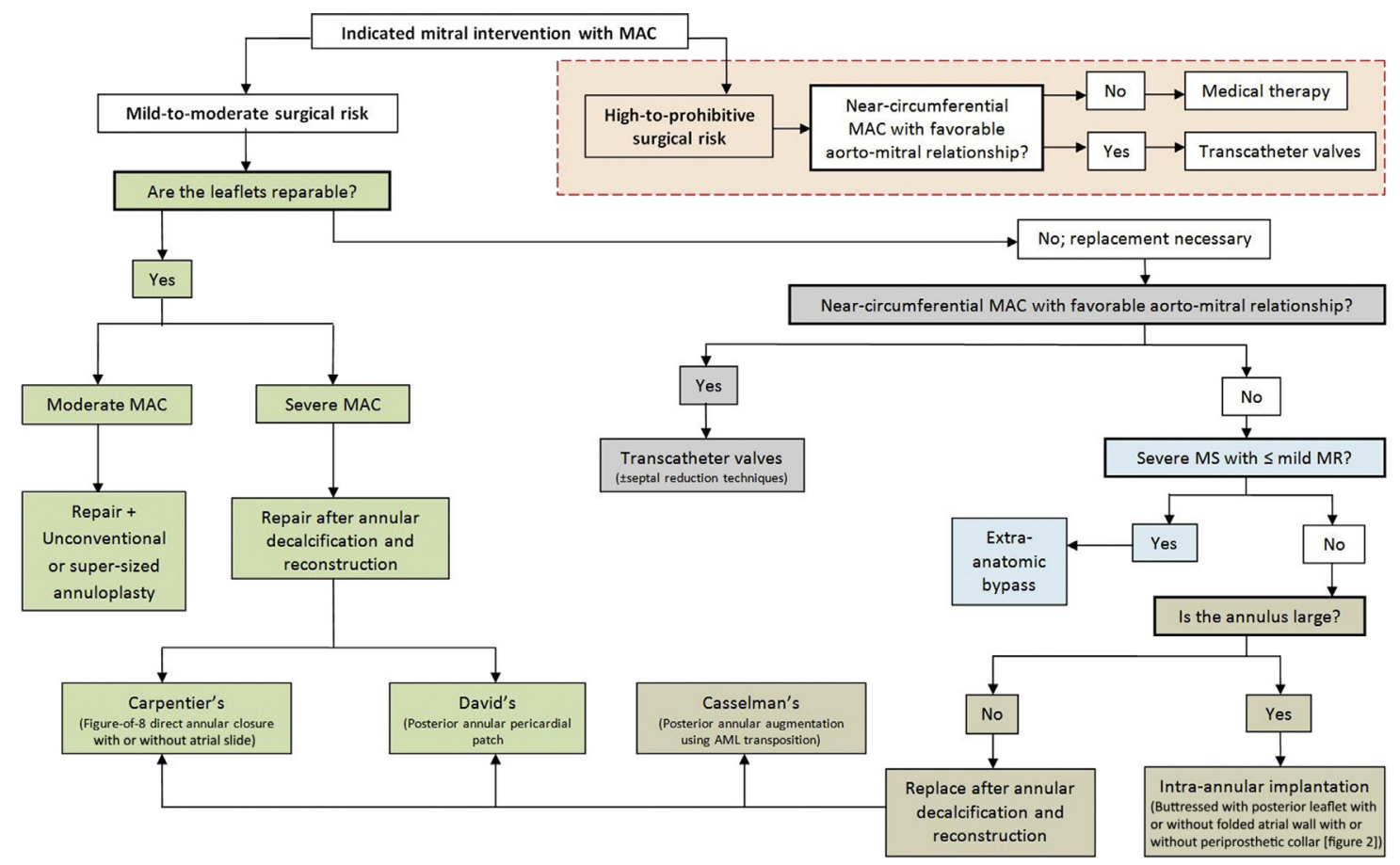

FIGURE 6. Proposed approach to mitral valve intervention in nonfocal moderate to severe mitral annular calcification $(M A C)$ with no prohibitive surgical risk. $A M L$, Anterior mitral leaflet; $M S$, mitral stenosis; $M R$, mitral regurgitation.

safer. The Transcatheter Mitral Valve Replacement with Medtronic Intrepid TMVR System in Patients with Severe Symptomatic Mitral Regurgitation (APOLLO) trial is a randomized trial testing the Interpid valve (Medtronic), which is designed for the mitral position. Enrollment of 1380 patients is expected and will include 3 arms; a surgical mitral valve replacement arm, a TMVR arm in surgical candidates, and TMVR in patients with prohibitive surgical risk. Although this study will exclude patients with MAC, changes in the exclusion criteria are expected to allow some degree of MAC. Results of this randomized study will throw light on the performance of TMVR with its various approaches and potentially pave the way for further adoption. The Mitral Implantation of TRAnscatheter valves (MITRAL) study is prospectively enrolling nonoperable patients for TMV in MAC, degenerated bioprosthetic valve, or failed annuloplasty ring. The primary completion date is expected to be within this year, and will provide further understanding of TMVR in MAC patients.

Our center's experience with transcatheter techniques in MAC patients is evolving. We have performed $6 \mathrm{TMV}$ replacements. One was performed using the transatrial approach, and the rest via the trans-septal approach. The procedure itself was successful in all cases, however there is still a lot to understand regarding patient selection, anatomy, and risk assessment of LVOTO. This is a promising technology, and more supporting data with experience will tell us whether this will be the standard care in these high-risk patients.

\section{SUMMARY AND FUTURE DIRECTIONS}

The variety of techniques proposed for addressing MAC testifies to the complexity of this problem. Unfortunately, most of these are single-center reports of singular techniques, which do not offer comparative data on the performance of one technique over the other. Also, different techniques require varying degrees of surgical and institutional expertise and capabilities, thus, being realistic in assessing these is very important to achieve optimal outcomes. Our proposed algorithm to approach patients with severe MAC is illustrated (Figure 6). For patients who are deemed high risk or not eligible for surgery, either transcatheter valves or palliative medical therapy should be considered. There is no comparison between both approaches yet but the data available, the refinement of techniques in preventing LVOTO, and the anticipated results from the MITRAL study might make transcatheter valves an excellent option for these patients who cannot undergo surgery.

For patients with a low to moderate surgical risk, the decision is more complex. Advantages and disadvantages of different surgical approaches are summarized in Table 1. Unlike the aortic valve, repair is the optimal strategy for MVs. We believe that even with MAC, valve repair should 
TABLE 1. Summary of advantages and disadvantages of surgical strategies to address the annulus with severe MAC

\begin{tabular}{|c|c|c|}
\hline & Working around the calcified annulus (respect) & Decalcification and annular reconstruction (resect) \\
\hline Advantages & $\begin{array}{l}\text { - Simpler and shorter surgeries } \\
\text { - Lower risk of AV groove disruption } \\
\text { - TMVR: possible percutaneous approach, promising }\end{array}$ & $\begin{array}{l}\text { - Allow for natural prosthesis size and position } \\
\text { - More likely to allow valve repair vs replacement (except } \\
\text { for the Cleveland Clinic technique) } \\
\text { - Less risk of PVLs and higher likelihood of healing mild } \\
\text { PVLs }\end{array}$ \\
\hline Disadvantages & $\begin{array}{l}\text { - Replacement as opposed to repair (except for untraditional } \\
\text { and supersized annuloplasty, on the basis of configuration } \\
\text { of calcium) } \\
\text { - Higher PVLs that are less likely to heal } \\
\text { - Suture around calcium: risk of injury to circumflex artery, } \\
\text { and less commonly conduction system or coronary sinus } \\
\text { - Intra-annular: smaller sized valve and high PVLs } \\
\text { - Supra-annular: PVLs with atrial rupture due to subjection } \\
\text { to ventricular pressures } \\
\text { - Combined intra and supra-annular (with or without } \\
\text { collar): significant valve downsizing } \\
\text { - Extra-anatomic bypass: only with stenosis, unphysiologic, } \\
\text { last resort } \\
\text { - TMVR: experimental, requires dense near- } \\
\text { circumferential MAC, unknown long-term durability }\end{array}$ & $\begin{array}{l}\text { - Technically challenging } \\
\text { - Longer CPB and clamp times } \\
\text { - Low but real risk of AV groove disruption }\end{array}$ \\
\hline
\end{tabular}

$\overline{A V}$, Atrioventricular; $T M V R$, transcatheter mitral valve replacement; $P V L$, paravalvular leak; $M A C$, mitral annular calcification; $C P B$, cardiopulmonary bypass.

be the preferred choice. With less dense calcification, either an unconventional or a super-sized annuloplasty ring can be mounted without the need to decalcify the annulus. If decalcification is required, either the Carpentier or the David method should be done as described previously. If repair is known to be less likely successful on the basis of preoperative data, then evaluation for suitability for transcatheter valves is the next step. The extent to which annular calcification is required is unclear, and might decrease with future mitral-specific transcatheter prostheses surfacing that will not need a rigid annular anchor. Suitability of the LVOT and aorto-mitral angles should also be assessed using thin-sliced cardiac CT. In the unfortunate patient who has a low likelihood for repair and anatomy that precludes TMVs, less optimal options need to be undertaken. If the main pathology is severe stenosis and not more than mild regurgitation, extra-anatomic bypasses might be considered. If the annulus is known to be large, a combination of intra-annular and supraannular implantation should be done, as illustrated in Figure 4, $C$ and $D$. We certainly do not recommend or see the need to ever perform a purely intra-annular or a purely intra-atrial implantation. If the annulus is not large enough to accommodate either technique, then decalcification becomes necessary, and in addition to the Carpentier and David methods, anterior mitral leaflet transposition patching can be used. We believe reconstructing the annulus followed by a replacement combines the worst of both worlds and should only be done when absolutely necessary.

\section{Conflict of Interest Statement}

Authors have nothing to disclose with regard to commercial support.

\section{References}

1. Allam AH, Thompson RC, Wann LS, Miyamoto MI, Nur El-Din Ael H, El-Maksoud GA, et al. Atherosclerosis in ancient Egyptian mummies: the Horus study. JACC Cardiovasc Imaging. 2011;4:315-27.

2. Que YA, Oddo M, Liaudet L, Moreillon P. Infective endocarditis: update [in French]. Rev Med Suisse Romande. 2004;124:341-6.

3. Fox E, Harkins D, Taylor H, McMullan M, Han H, Samdarshi T, et al. Epidemiology of mitral annular calcification and its predictive value for coronary events in African Americans: the Jackson cohort of the atherosclerotic risk in communities study. Am Heart J. 2004;148:979-84.

4. Savage DD, Garrison RJ, Castelli WP, McNamara PM, Anderson SJ, Kannel WB, et al. Prevalence of submitral (anular) calcium and its correlates in a general population-based sample (the Framingham Study). Am J Cardiol. $1983 ; 51: 1375-8$.

5. Fox CS, Vasan RS, Parise H, Levy D, O’Donnell CJ, D’Agostino RB, et al. Mitral annular calcification predicts cardiovascular morbidity and mortality: the Framingham heart study. Circulation. 2003;107:1492-6.

6. Roberts WC. Morphologic features of the normal and abnormal mitral valve. Am J Cardiol. 1983;51:1005-28.

7. Roberts WC. Complications of cardiac valve replacement: characteristic abnormalities of prostheses pertaining to any or specific site. Am Heart J. 1982;103:113-22.

8. Roberts WC, Morrow AG. Causes of early postoperative death following cardiac valve replacement. Clinico-pathologic correlations in 64 patients studied at necropsy. J Thorac Cardiovasc Surg. 1967;54:422-37.

9. MacVaugh H III, Joyner CR, Johnson J. Unusual complications during mitral valve replacement in the presence of calcification of the annulus. Ann Thorac Surg. 1971;11:336-42. 
10. Carpentier AF, Pellerin M, Fuzellier JF, Relland JY. Extensive calcification of the mitral valve anulus: pathology and surgical management. J Thorac Cardiovasc Surg. 1996;111:718-29; discussion 29-30.

11. Eleid MF, Foley TA, Said SM, Pislaru SV, Rihal CS. Severe mitral annular calcification: multimodality imaging for therapeutic strategies and interventions. JACC Cardiovasc Imaging. 2016;9:1318-37.

12. Movva R, Murthy K, Romero-Corral A, Seetha Rammohan HR, Fumo P, Pressman GS. Calcification of the mitral valve and annulus: systematic evaluation of effects on valve anatomy and function. J Am Soc Echocardiogr. 2013; 26:1135-42.

13. Kohsaka S, Jin Z, Rundek T, Boden-Albala B, Homma S, Sacco RL, et al. Impact of mitral annular calcification on cardiovascular events in a multiethnic community: the Northern Manhattan study. JACC Cardiovasc Imaging. 2008;1:617-23.

14. Sell S, Scully RE. Aging changes in the aortic and mitral valves. Histologic and histochemical studies, with observations on the pathogenesis of calcific aortic stenosis and calcification of the mitral annulus. Am J Pathol. 1965;46:345-65.

15. Kanjanauthai S, Nasir K, Katz R, Rivera JJ, Takasu J, Blumenthal RS, et al. Relationships of mitral annular calcification to cardiovascular risk factors: the multi-ethnic study of atherosclerosis (MESA). Atherosclerosis. 2010;213: 558-62.

16. Adler Y, Fink N, Spector D, Wiser I, Sagie A. Mitral annulus calcification-a window to diffuse atherosclerosis of the vascular system. Atherosclerosis. 2001;155: $1-8$.

17. Roberts WC. The senile cardiac calcification syndrome. Am J Cardiol. 1986;58: $572-4$.

18. Boon A, Cheriex E, Lodder J, Kessels F. Cardiac valve calcification: characteristics of patients with calcification of the mitral annulus or aortic valve. Heart. 1997:78:472-4

19. Nestico PF, Depace NL, Morganroth J, Kotler MN, Ross J. Mitral annular calcification: clinical, pathophysiology, and echocardiographic review. Am Heart J. 1984;107:989-96.

20. Roberts WC, Perloff JK. Mitral valvular disease. A clinicopathologic survey of the conditions causing the mitral valve to function abnormally. Ann Intern Med. 1972:77:939-75.

21. Silbiger JJ. Anatomy, mechanics, and pathophysiology of the mitral annulus. Am Heart J. 2012;164:163-76.

22. Elmariah S, Delaney JA, Bluemke DA, Budoff MJ, O'Brien KD, Fuster V, et al. Associations of LV hypertrophy with prevalent and incident valve calcification: multi-ethnic study of atherosclerosis. JACC Cardiovasc Imaging. 2012;5:781-8.

23. Fusini L, Ghulam Ali S, Tamborini G, Muratori M, Gripari P, Maffessanti F, et al. Prevalence of calcification of the mitral valve annulus in patients undergoing surgical repair of mitral valve prolapse. Am J Cardiol. 2014;113:1867-73.

24. Michel PL, Vitoux B, Dermine P, Hage A, Pezzano M, Ghanem G, et al. Mitral calcification in aortic stenosis. Eur Heart J. 1988;9(Suppl E):77-82.

25. Fox CS, Parise H, Vasan RS, Levy D, O'Donnell CJ, D'Agostino RB, et al. Mitral annular calcification is a predictor for incident atrial fibrillation. Atherosclerosis. 2004; 173:291-4.

26. Takamoto T, Popp RL. Conduction disturbances related to the site and severity of mitral anular calcification: a 2-dimensional echocardiographic and electrocardiographic correlative study. Am J Cardiol. 1983;51:1644-9.

27. Maher ER, Young G, Smyth-Walsh B, Pugh S, Curtis JR. Aortic and mitral valve calcification in patients with end-stage renal disease. Lancet. 1987;2:875-7.

28. Sharma R, Pellerin D, Gaze DC, Mehta RL, Gregson H, Streather CP, et al. Mitral annular calcification predicts mortality and coronary artery disease in end stage renal disease. Atherosclerosis. 2007;191:348-54

29. Ix JH, Shlipak MG, Katz R, Budoff MJ, Shavelle DM, Probstfield JL, et al. Kidney function and aortic valve and mitral annular calcification in the multi-ethnic study of atherosclerosis (MESA). Am J Kidney Dis. 2007;50:412-20.

30. Fox CS, Larson MG, Vasan RS, Guo CY, Parise H, Levy D, et al. Cross-sectional association of kidney function with valvular and annular calcification: the Framingham heart study. J Am Soc Nephrol. 2006;17:521-7.

31. Umana E, Ahmed W, Alpert MA. Valvular and perivalvular abnormalities in endstage renal disease. Am J Med Sci. 2003;325:237-42.

32. Heidenreich PA, Hancock SL, Lee BK, Mariscal CS, Schnittger I. Asymptomatic cardiac disease following mediastinal irradiation. J Am Coll Cardiol. 2003;42: 743-9.

33. Nielsen KM, Offersen BV, Nielsen HM, Vaage-Nilsen M, Yusuf SW. Short and long term radiation induced cardiovascular disease in patients with cancer. Clin Cardiol. 2017:40:255-61.

34. Desai MY, Wu W, Masri A, Popovic ZB, Agarwal S, Smedira NG, et al. Increased aorto-mitral curtain thickness independently predicts mortality in patients with radiation-associated cardiac disease undergoing cardiac surgery. Ann Thorac Surg. 2014;97:1348-55.

35. Radke RM, Baumgartner H. Diagnosis and treatment of Marfan syndrome: an update. Heart. 2014;100:1382-91.

36. Schieken RM, Kerber RE, Ionasescu VV, Zellweger H. Cardiac manifestations of the mucopolysaccharidoses. Circulation. 1975;52:700-5.

37. Correia J, Rodrigues D, da Silva AM, Sá e Melo A, Providencia LA. Massive calcification of the mitral valve annulus in an adolescent with Marfan syndrome. A case report. Rev Port Cardiol. 2006;25:921-6.

38. Chan V, Ruel M, Hynes M, Chaudry S, Mesana TG. Impact of mitral annular calcification on early and late outcomes following mitral valve repair of myxomatous degeneration. Interact Cardiovasc Thorac Surg. 2013;17:120-5.

39. Feindel CM, Tufail Z, David TE, Ivanov J, Armstrong S. Mitral valve surgery in patients with extensive calcification of the mitral annulus. J Thorac Cardiovasc Surg. 2003;126:777-82.

40. Cho IJ, Moon J, Shim CY, Jang Y, Chung N, Chang BC, et al. Differen clinical outcome of paravalvular leakage after aortic or mitral valve replacement. Am J Cardiol. 2011;107:280-4.

41. Subramanian S, Borger MA. Management of heavily calcified mitral and aortic annuli. In: Franco KL, Thourani VH, eds. Cardiothoracic Surgery Review. 1st ed. Philadelphia: Lippincott Williams and Wilkins; 2012:261-3.

42. Casselman FP, Gillinov AM, McDonald ML, Cosgrove DM III. Use of the anterior mitral leaflet to reinforce the posterior mitral annulus after debridement of calcium. Ann Thorac Surg. 1999;68:261-2.

43. Yoon SH, Whisenant BK, Bleiziffer S, Delgado V, Schofer N, Eschenbach L, et al. Transcatheter mitral valve replacement for degenerated bioprosthetic valves and failed annuloplasty rings. J Am Coll Cardiol. 2017;70:1121-31.

44. Guerrero M, Dvir D, Himbert D, Urena M, Eleid M, Wang DD, et al. Transcatheter mitral valve replacement in native mitral valve disease with severe mitra annular calcification: results from the first multicenter global registry. JACC Cardiovasc Interv. 2016;9:1361-71.

45. Grossi EA, Galloway AC, Steinberg BM, LeBoutillier M III, Delianides J, Baumann FG, et al. Severe calcification does not affect long-term outcome of mitral valve repair. Ann Thorac Surg. 1994;58:685-7; discussion 688.

46. Nishimura RA, Otto CM, Bonow RO, Carabello BA, Erwin JP III, Guyton RA, et al. 2014 AHA/ACC guideline for the management of patients with valvular heart disease: a report of the American College of Cardiology/American Hear Association task force on practice guidelines. Circulation. 2014;129:e521-643.

47. Suri RM, Schaff HV, Dearani JA, Sundt TM III, Daly RC, Mullany CJ, et al. Survival advantage and improved durability of mitral repair for leaflet prolapse subsets in the current era. Ann Thorac Surg. 2006;82:819-26.

48. Gillinov AM, Cosgrove DM, Blackstone EH, Diaz R, Arnold JH Lytle BW, et al. Durability of mitral valve repair for degenerative disease J Thorac Cardiovasc Surg. 1998;116:734-43.

49. Flameng W, Herijgers $P$, Bogaerts $K$. Recurrence of mitral valve regurgitation after mitral valve repair in degenerative valve disease. Circulation. 2003;107:1609-13.

50. Ng CK, Punzengruber C, Pachinger O, Nesser J, Auer H, Franke H, et al. Valve repair in mitral regurgitation complicated by severe annulus calcification. Ann Thorac Surg. 2000;70:53-8.

51. d'Alessandro C, Vistarini N, Aubert S, et al. Mitral annulus calcification: determinants of repair feasibility, early and late surgical outcome. Eur J Cardiothorac Surg. 2007;32:596-603.

52. Chauvaud S, Jebara V, Chachques JC, Jault F, Acar C, Pavie A, et al. Valve extension with glutaraldehyde-preserved autologous pericardium. Results in mitra valve repair. J Thorac Cardiovasc Surg. 1991;102:171-7; discussion 177-8.

53. Maisano F, Caldarola A, Blasio A, De Bonis M, La Canna G, Alfieri O. Midterm results of edge-to-edge mitral valve repair without annuloplasty. J Thorac Cardiovasc Surg. 2003;126:1987-97.

54. Mihaljevic T, Koprivanac M, Kelava M, Smedira NG, Lytle BW, Blackstone EH Mitral valve replacement in patients with severely calcified mitral annulus: surgical technique. J Thorac Cardiovasc Surg. 2013;146:233-5.

55. Carpentier AA, Filsoufi F, eds. Carpentier's Reconstructive Valve Surgery. Philadelphia: Saunders Elsevier; 2010.

56. Unal M, Sanisoglu I, Konuralp C, Akay H, Orhan G, Aydogan H, et al. Ultrasonic decalcification of calcified valve and annulus during heart valve replacement. Tex Heart Inst J. 1996;23:85-7.

57. Vander Salm TJ, Perras M. As originally published in 1989: mitral annular calcification: a new technique for valve replacement. Updated in 1997. Ann Thorac Surg. 1997;63:1819-20.

58. Baumgartner FJ, Pandya A, Omari BO, Turner C, Milliken JC, Robertson JM Ultrasonic debridement of mitral calcification. J Card Surg. 1997;12:240-2. 
59. Uchimuro T, Fukui T, Shimizu A, Takanashi S. Mitral valve surgery in patients with severe mitral annular calcification. Ann Thorac Surg. 2016;101:889-95.

60. Chen CW, Chung JJ, Gaffey AC, Hargrove WC, Acker MA, Atluri P. Mitral valve surgery can be safely performed in the presence of significant mitral annular calcification. Presented at: 2017 AATS Mitral Conclave; April 27-28, 2017; New York, NY.

61. Coselli JS, Crawford ES. Calcified mitral valve annulus: prosthesis insertion. Ann Thorac Surg. 1988;46:584-6.

62. Di Stefano S, Lopez J, Florez S, Rey J, Arevalo A, San Roman A. Building a new annulus: a technique for mitral valve replacement in heavily calcified annulus. Ann Thorac Surg. 2009;87:1625-7.

63. Okita Y, Miki S, Ueda Y, Tahata T, Sakai T, Matsuyama K. Mitral valve replacement with a collar-reinforced prosthetic valve for disrupted mitral annulus. Ann Thorac Surg. 1995;59:187-9.

64. El-Eshmawi A, Love B, Bhatt HV, Pawale A, Boateng P, Adams DH. Direct acces implantation of Melody valve in native mitral valve: a hybrid approach in the presence of extensive mitral annular calcification. Ann Thorac Surg. 2015;99:1085.

65. Mills NL, McIntosh CL, Mills LJ. Techniques for management of the calcified mitral annulus. J Card Surg. 1986;1:347-55.

66. Gandjbakhch I, Lascar M, Pavie A, Cabrol C. Intra-atrial insertion of a prosthetic mitral valve. J Cardiovasc Surg (Torino). 1988;29:113-4.

67. Nataf P, Pavie A, Jault F, Bors V, Cabrol C, Gandjbakhch I. Intraatrial insertion of a mitral prosthesis in a destroyed or calcified mitral annulus. Ann Thorac Surg. 1994;58:163-7.

68. Hussain ST, Idrees J, Brozzi NA, Blackstone EH, Pettersson GB. Use of annulus washer after debridement: a new mitral valve replacement technique for patients with severe mitral annular calcification. J Thorac Cardiovasc Surg. 2013;145: $1672-4$.
69. Wright JS, Thomson DS, Warner G. Mitral valve bypass by valved conduit. Ann Thorac Surg. 1981;32:294-6.

70. Said SM, Schaff HV. An alternate approach to valve replacement in patients with mitral stenosis and severely calcified annulus. J Thorac Cardiovasc Surg. 2014; 147:e76-8.

71. El Sabbagh A, Eleid MF, Foley TA, Al-Hijji MA, Daly RC, Rihal CS, et al. Direct transatrial implantation of balloon-expandable valve for mitral stenosis with severe annular calcifications: early experience and lessons learned. Eur J Cardiothorac Surg. 2018;53:162-9.

72. Lee R, Fukuhara S, George I, Borger MA. Mitral valve replacement with a transcatheter valve in the setting of severe mitral annular calcification. J Thorac Cardiovasc Surg. 2016;151:e47-9.

73. Forcillo J, Babaliaros V, Thourani VH. A very elegant transcatheter strategy for complicated mitral valve replacement associated with severe mitral annular calcification. J Thorac Cardiovasc Surg. 2016;151:e49-50.

74. Alkhouli M, Rihal CS, Zack CJ, Eleid MF, Maor E, Sarraf M, et al. Transcatheter and surgical management of mitral paravalvular leak: long-term outcomes. JACC Cardiovasc Interv. 2017;10:1946-56.

75. Hongxin L, Wenbin G, Zhang HZ, Liang F, Yuan GD, Farhaj Z, et al. Peratrial device closure of different locations of mitral paravalvular leaks. Ann Thorac Surg. 2018:105:1710-6.

76. Babaliaros VC, Greenbaum AB, Khan JM, Rogers T, Wang DD, Eng MH, et al. Intentional percutaneous laceration of the anterior mitral leaflet to prevent outflow obstruction during transcatheter mitral valve replacement: first-inhuman experience. JACC Cardiovasc Interv. 2017;10:798-809.

77. Rahhab Z, Ren B, de Jaegere PP, Van Mieghem NM. Kissing balloon technique to secure the neo-left ventricular outflow tract in transcatheter mitral valve implantation. Eur Heart J. 2018:39:2220. 